\title{
Safety of Low Dose of Edoxaban to Treat Acute and Long Term Treatment of a VTE Occurred in a Very Young Adolescent
}

\section{Pierpaolo Di Micco* and Gianluca Di Micco²}

${ }^{1}$ Department of Medicine, UOC Internal Medicine, Ospedale Fatebenefratelli di Napoli, Napoli, Italy

${ }^{2}$ Department of Medicine, UO Cardiology, Ospedale Fatebenefratelli di Napoli, Napoli, Italy

\begin{abstract}
The treatment of VTE with direct oral anticoagulant (DOACs) is a common treatment and therapeutic regimens and timing of treatment are well documented by international guidelines both for initial therapy and for extended therapy. Suggested doses of each drug are established after dose-findings studies and thereafter after phase III clinical trials. Suggested doses of edoxaban to treat VTE are based on $60 \mathrm{mg}$ daily while other available dosages, in particular $30 \mathrm{mg}$ daily are suggested if patients show impaired renal function with moderate kidney failure, low body weight or concomitant use of P-glycoprotein inhibitor drugs. However, there are not studies concerning the optimal treatment with any DOACs and in particular for edoxaban for patients aged less than 18 years, because in dose findings studies and in phase III trials alle selected subjects were major than 18 years old; these informations are also lacking in the Literature concerning real life studies too (e.g., case reports and so on). So $30 \mathrm{mg}$ daily of edoxaban for patients younger than 18 years may be considered an off label target. Moreover the off label dosage of $30 \mathrm{mg}$ daily of edoxaban to treat juvenile VTE is related not only to young age but also to other clinical characteristics as juvenile metabolism and body weight and BMI, gastrointestinal absorption and renal and liver metabolism. This report may so add useful information for a next future application of this kind of drugs also in young patients affected by VTE.
\end{abstract}

\section{Introduction}

According to the most recent guidelines, direct oral anticoagulants (DOACs) became the mainstay of treatment and of secondaryprevention of venous thromboembolic events (VTE) [1]. A number of randomized controlled trials (RCTs) and meta-analyses have clearly shown that DOACs are at least effective and safe as vitamin $\mathrm{k}$ antagonists (VKAs) in patients with acute VTE [2-7]. So, International guidelines of several scientific societies as American College of Chest Physician (ACCP) suggest to treat VTE with direct oral anticoagulants (DOACs) versus other anticoagulants as low molecular weight heparins, fondaparinux or antivitamin $\mathrm{K}(\mathrm{AVK})$ antagonists both in acute phase and also for long term treatment [1]. Edoxaban is one of available DOACs useful to treat VTE and it exerts its anticoagulant activity toward clotting factor $\mathrm{Xa}$ [8]. Suggested dosages of each drug and so also for edoxaban have been tested by premarketing studies as dose finding studies [9] and as phase III clinical trials [4]. However, current international guidelines as ACCP guidelines do not offer suggestion to treat juvenile VTE and or VTE occurring at pediatric age; furthermore, few information are also available for the treatment of VTE in juvenile age with all type of DOACs because all patients selected for phase III trials were major than 18 years; this information is actually lacking also in the Literature as real world data as case report or case series. So we here report a case a young patient affected by spontaneous VTE treated by reduced doses of edoxaban both in acute phase and in long term treatment and that has good outcomes after 1 year of treatment.

\section{Case History}

A young male of 14 years felt right lower limb pain associated to oedema of foot and weariness. He referred reduced mobility of the same leg due to non-surgical trauma of right lower leg during physical exercise four days before. Because the pain was not improved after NSAIDs and the oedema was extended to the full leg an ultrasound scan was performed and revealed a proximal deep vein thrombosis (DVT). He is $168 \mathrm{~cm}$ with a weight of $49 \mathrm{~kg}$ so his BMI was low (i.e., 17); moreover, he is a nonsmoker boy, without recent surgical approach and his personal anamnesis was negative for previous vascular disease; similar information were detected in his first degree relatives. After ultrasound scan blood samples were performed and revealed normal function of kidney and liver, nor abnormalities of PT, aPTT and platelet count. Because his young age without the presence of conventional thrombotic risk factors for VTE inherited thrombophilia was looked for and revealed the presence of heterozigosity of prothrombin A20210G gene polymorphism; other molecular thrombophilia's were not detected. According to international guidelines acute treatment of DVT was based on enoxaparing $40 \mathrm{mg}$ twice daily with the suggestion to go on with anti-vitamin $\mathrm{K}$ drugs as warfaring for long term treatment; yet after first three days of treatment he did not agree to go on with warfarin and his parents too. So, we planned to perform an extended treatment with reduced doses of edoxaban $30 \mathrm{mg}$ daily. Clinical response was good with a good tolerance of drug. Haemocrome and kidney function were checked several times during the treatment without relevant alteration. Moreover, from an instrumental point of view full recanalisation of lower limb DVT was detected after the first month of therapy and following controls after 6 months revealed a slight post- thrombotic syndrome according with Villalta score. Actually after ten months of therapy the main outcomes of a VTE treatment, (i.e., major bleedings and recurrent VTE) were both safe.

\section{Discussion}

Juvenile VTE is very rare an antithrombotic treatment in this

*Corresponding author: Micco PD, Department of Medicine, UOC Internal Medicine, Ospedale Fatebenefratelli di Napoli, Napoli, Italy, Tel: 00393398078146; E-mail: pdimicco@libero.it

Received November 19, 2017; Accepted November 22, 2017; Published November 29, 2017

Citation: Micco PD, Micco GD (2017) Safety of Low Dose of Edoxaban to Treat Acute and Long Term Treatment of a VTE Occurred in a Very Young Adolescent. J Blood Lymph 7: 191. doi:10.4172/2165-7831.1000191

Copyright: $\odot 2017$ Micco PD, et al. This is an open-access article distributed unde the terms of the Creative Commons Attribution License, which permits unrestricted use, distribution, and reproduction in any medium, provided the original author and source are credited. 
Citation: Micco PD, Micco GD (2017) Safety of Low Dose of Edoxaban to Treat Acute and Long Term Treatment of a VTE Occurred in a Very Young Adolescent. J Blood Lymph 7: 191. doi:10.4172/2165-7831.1000191

Page 2 of 5

clinical condition is very difficult because there are not clinical studies about this topic or international guidelines. Although DOACs are the suggested drugs to treat VTE, there is not info on pre-marketing studies or guidelines that testify the efficacy and safety of these drugs in patients aged less than 18 years. On the other hand, juvenile patients may show usually such of any condition that are reported as critical for the use of DOACs as low BMI [10]. Furthermore, pharmacokinetic of edoxaban could be different in adolescent because different bowel absorption and kidney clearance [11]. So, modified doses of anticoagulant may be taken in consideration according to different BMI and juvenile metabolism if VTE is present. For this reason the dose that we choose in this case was lower than that suggested for adult patient (i.e., $30 \mathrm{mg}$ daily). During the following clinical evaluations we found that reduced doses of edoxaban showed not only a good compliance for the patients without a specific side effect as gastrointestinal disorders but also a relevant safety concerning main outcomes as thrombotic resolution as prevention of recurrent VTE as major bleeding. Actually this is the first report in the Literature concerning the use of reduced doses of edoxaban in juvenile VTE and because this aspect and the reported additional clinical characteristics it may be very useful for further use. Moreover, further studies on larger population and in double blind or longer clinical series are needed in order to confirm the information reported in this case in particular concerning doses of DOACs in the treatment of juvenile VTE.

\section{References}

1. Kearon C, Akl EA, Ornelas J, Blaivas A, Jimenez D, et al. (2016) Antithrombotic Therapy for VTE Disease: CHEST Guideline and Expert Panel Report. Chest 149: 315-352.
2. Schulman S, Kearon C, Kakkar AK, Mismetti P, Schellong S, et al. (2009) Dabigatran versus warfarin in the treatment of acute venous thromboembolism. N Engl J Med 361: 2342-2352.

3. Schulman S, Kakkar AK, Goldhaber SZ, Schellong S, Eriksson H, et al. (2014 Treatment of acute venous thromboembolism with dabigatran or warfarin and pooled analysis. Circulation 129: 764-772.

4. Hokusai-VTE Investigators, Büller HR, Décousus H, Grosso MA, Mercuri M, et al. (2013) Edoxaban versus warfarin for the treatment of symptomatic venous thromboembolism. N Engl J Med 369: 1406-1415.

5. Agnelli G, Buller HR, Cohen A, Curto M, Gallus AS, et al. (2013) Oral apixaban for the treatment of acute venous thromboembolism. N Engl J Med 369: 799-808.

6. Einstein-Pe Investigators, Büller HR, Prins $M H$, Lensin AW, Decousus $H$, et al (2012) Oral rivaroxaban for the treatment of symptomatic pulmonary embolism. N Engl J Med 366: 1287-1297.

7. Einstein Investigators, Bauersachs R, Berkowitz SD, Brenner B, Buller HR, et al. (2010) Oral rivaroxaban for symptomatic venous thromboembolism. N Engl J Med 363: 2499-2510.

8. Parasrampuria DA, Mendell J, Shi M, Matsushima N, Zahir H, et al. (2016) Edoxaban drug-drug interactions with ketoconazole, erythromycin, and cyclosporine. Br J Clin Pharmacol 82: 1591-1600.

9. Lip GY, Agnelli G (2014) Edoxaban: a focused review of its clinical pharmacology. Eur Heart J 35: 1844-1855.

10. Moustafa F, Pesavento R, Micco PD, Gonzalez-Martinez J, Quintavalla R, et al (2017) Real-life use of anticoagulants in venous thromboembolism with a focus on patients with exclusion criteria for direct oral anticoagulants. Clin Pharmacol Ther.

11. Switzer MP, Wani P, Gosavi S, Mukherjee D (2015) Clinical pharmacology and role of edoxaban in contemporary antithrombotic therapy. Cardiovasc Hematol Agents Med Chem 13: 98-104. 